\title{
Padre António Vieira: o discurso engenhoso em nome da fé e da salvação do homem*1
}

\author{
Nadiá Paulo Ferreira*2
}

No século XVII, o sermão é a via da evangelização do catolicismo. Baltazar Gracián, o grande teórico da retórica barroca, elabora as normas do discurso engenhoso: um saber fazer com a palavra, um trabalho de reconstrução da lingua. Em seus sermões, padre António Vieira coloca o engenho a serviço de um discurso que se inscreve em uma das versões míticas sobre Portugal: uma nação cujo povo espera com a ressurreição de Dom Sebastião, o rei morto na batalha de Alkácer Kibir, reconquistar o passado glorioso da época dos descobrimentos.

Palavras-chave: Barroco, delírio, paranoia, Nome-do-Pai

*1Trabalho apresentado no V Encontro Nacional \& V Colóquio Internacional (Belém, PA): O inconsciente a céu aberto: as psicoses na psicanálise (30 e 31 de outubro e 1 de novembro de 2015).

*2Universidade do Estado de Rio de Janeiro - UERJ (Rio de Janeiro, RJ, Br) 
Na Europa, durante o século XVII, três grandes transformações abalam os laços sociais entre os homens: a revolução comercial, o fortalecimento do poder real (absolutismo) e a formação dos grandes impérios coloniais.

Nesse cenário, a teoria do modelo heliocêntrico de Copérnico (1473-1543), a Reforma Protestante (1517), liderada por Lutero (1483-1546), e a autonomeação de chefe da Igreja da Inglaterra por Henrique VIII (1491-1547) ameaçam a unidade católica na Europa, colocando em xeque o poder eclesiástico de Roma.

A Igreja Católica Romana reage com a criação do movimento da Contrarreforma, o qual desencadeou uma série de medidas. Dentre elas, destacamos a criação da ordem religiosa Companhia de Jesus (1534) por Inácio de Loyola, da qual o Padre António Vieira (Lisboa, 6 de fevereiro de 1608-Salvador, 18 de julho de 1697) pertencia e o Concílio de Trento (1545 e 1563), o qual foi responsável por uma série de medidas. Dentre elas, destacamos a reativação do Tribunal do Santo Ofício a Inquisição, e a criação da lista dos livros proibidos (Index Librorum Prohibitorum).

Nos países católicos, um novo estilo nasce da aliança entre os poderes eclesiástico e secular: o barroco, cuja função social é a propagação da fé e do catolicismo. A oratória se torna a via de evangelização do catolicismo. Esse estilo, que tem em Baltazar Gracián o seu grande teórico, cria uma nova noção de belo, em que as regras da eloquência se tornam o suporte de um trabalho com a palavra, que produz a noção de um discurso engenhoso.

Para o barroco, discurso é sinônimo de um saber fazer com a palavra, de um trabalho de reconstrução da língua. É preciso mestria para usar as ferramentas retóricas na construção de figuras que têm como função o ornamento. A presença do belo 
está diretamente ligada à ornamentação do discurso. O efeito produzido pela mensagem no destinatário depende não do que é dito, mas do modo pelo qual se diz. Neste sentido, podemos afirmar que os sermões do padre António Vieira não só têm o engenho como atributo, mas também são o meio pelo qual ele acredita que irá transformar o mundo e salvar o homem. É a crença inabalável nessa missão de origem divina que irá determinar o que poderíamos chamar de sintomas, que comparecem em seus sermões, fazendo com que possamos hipoteticamente inscrevê-los numa estrutura paranoica.

A constituição do eu humano, como Lacan já demonstrou no seu texto sobre o estágio do espelho, apresenta uma matriz paranoica. O que isto quer dizer? O eu se forma a partir de uma imagem especular, que se torna o suporte de todas as identificações imaginárias, as quais são reguladas por uma referência simbólica, caso tenha ocorrido, anteriormente, a inscrição do significante Nome-do-Pai.

É preciso que haja a intervenção da linguagem não só para ratificar o reconhecimento da própria imagem, mas também para que o outro, cuja imagem foi tomada como modelo, não seja reduzido à especularidade. É necessário que haja nesse outro, como semelhante, alguma coisa além da imagem. Ou seja: é preciso que haja para além do outro, o Outro que só pode ser apresentado como enigma sem decifração. É nesse sentido que se deve ler a axioma de Lacan: o desejo do homem é desejo do Outro.

$\mathrm{Na}$ paranoia, isto não ocorre porque a função simbólica é excluída do processo de formação do eu. O efeito desta exclusão implica uma dupla redução:

1. o Outro, como lugar dos significantes e portanto lugar fundante da alteridade, se converte no outro como semelhante;

2. o outro, como semelhante, se apresenta como reflexo do próprio eu no espelho, o que implica o apagamento de toda e qualquer diferença entre o eu e seus semelhantes.

A única via pela qual esse lugar (Outro), exterior a todos os seres falantes, comparece na estrutura paranoica é sob a forma de alusão a uma entidade, cujo atributo é a plenitude absoluta. Logo, esse Outro, envolvido em todo seu esplendor, só pode ser representado como onipotente e onipresente.

Vieira, em seus sermões, fala em nome de um Outro. Cabe, então, perguntar: quem fala em seus sermões, tomando a sua voz emprestada? Deus. Vieira, como porta voz deste Senhor Absoluto, se dirige a um mundo desordenado, a um mundo que caminha para a destruição. A sua missão, por ele ter tido o privilégio de ser o escolhido, é salvar os homens. 


\section{LITERATURA, PSICOPATOLOGIA}

Sem a inscrição do significante Nome-do-pai, humanizando um corpo vivo e cravando nele o traço da singularidade de um sujeito, temos uma fala sob o império dos signos, em que o real e o imaginário se cruzam. Estamos diante de um discurso delirante. Aqui, o significante perde o seu valor simbólico e passa a ser inflacionado por sentidos plenos e imanentes, fazendo com que as palavras adquiram vida. Diz Vieira no Sermão de Nossa Senhora do Ó, "na Igreja de Nossa Senhora da Ajuda, na Bahia, ano de 1640":

Uma das maiores excelências das Escrituras Divinas, é não haver nelas nem palavra, nem sílaba, nem ainda uma só letra, que seja supérflua, ou careça de mistério. Tal é o misterioso $\mathrm{O}$ que hoje começa a celebrar, e todos os dias repete a Igreja, breve na voz, grande na significação, e nos mistérios profundíssimos. (Vieira, 2001, Tomo I, p. 466)

O Sermão da Terceira Quarta-Feira da Quaresma, "pregado na Capela Real, no ano de 1670", tem como epígrafe um fragmento retirado de S. Mateus: Non est meum dare vobis, sed quibus paratum est a Patre meo ("não me pertence dá-lo, mas é para aqueles para quem meu Pai o tem preparado". (Mateus [20:2]). ${ }^{1}$

A proposição desse sermão é a palavra latina non, a qual é abordada como signo e não como significante. $\mathrm{O}$ argumento se baseia na suposição de que independente não só da estrutura da língua a que pertence, mas também do seu emprego no discurso, trata-se de uma palavra terrível, porque

(...) sempre é serpente, sempre morde, sempre fere, sempre leva o veneno consigo. Mata a esperança, que é o último remédio que deixou a natureza a todos os males. Não há corretivo que o modere, nem arte que o abrande, nem lisonja que o adoce. Por mais que o confeiteis; por mais que o enfeiteis sempre é feio; por mais que o doireis sempre é de ferro. Em nenhuma solfa ${ }^{2}$ o podeis pôr que não seja mal soante, áspero e duro. Quereis saber qual é a dureza de um não? A mais dura coisa que tem a vida é chegar a pedir e depois de chegar a pedir ouvir um não: vede o que será? A língua Hebraica, que é a que falou Adão, e a que mais naturalmente significa e declara a essência das coisas chama ao negar o que se pede, envergonhar a face. Assim disse Betsabé a Salomão; Petitionem unam precor a te, ne confundas faciem neam (uma só

${ }^{1}$ Este fragmento se encontra no seguinte contexto: "E diz-lhes ele: Na verdade bebereis o meu cálice, mas o assentar-se à minha direita ou à minha esquerda não me pertence dá-lo, mas é para aqueles para quem meu Pai o tem preparado".

${ }^{2}$ Solfa: solfejo, música vocal, cantiga, a parte musical do verso cantado. 
petição te faço; não ma rejeiteis): trago-vos, Senhor, uma petição, que não me envergonheis a face: E por que se chama envergonhar a face negar o que se pede? Porque dizer não a quem pede, é dar-lhe uma bofetada com a língua. Tão dura, tão áspera, tão injuriosa palavra é um não. Para a necessidade dura, para a honra afrontosa, e para o merecimento insofrível. (Vieira, 2001, Tomo I, p. 250)

Vieira vai buscar na materialidade fônica o que considera o ser da palavra, tornando sem efeito a função do significante no processo de significação. Logo, para este brilhante orador, as palavras ameaçam o homem em direção ao caminho do Bem, afastando-o de Deus. O vocábulo "non”.

Não tem direito nem avesso: por qualquer lado que o tomeis, sempre soa e diz o mesmo. Lede-o do principio para o fim, ou do fim para o principio, sempre é Non. (Vieira, 2001, Tomo I, p. 250)

E Vieira, imediatamente, vai interpretar a presença de somente três fonemas nessa palavra: "Quem fez Não tão breve, não quis que se dilatasse" (Vieira, 2001, Tomo 1, p. 252).

Quando se refere ao episódio de Moisés, ilustra o sentido dessa palavra sob a forma de congelamento e fixidez imutável:

Quando a vara de Moisés se converteu naquela serpente tão feroz, que fugia dela porque o não mordesse; disse-lhe Deus que a tomasse ao revés, e logo perdeu a figura, a ferocidade e a peçonha. O Non não é assim (...). (Vieira, 2001, Tomo 1, p. 250)

Os múltiplos significados da palavra Non não são resultados de uma operação metafórica, já que eles não são efeitos de uma substituição significante, mas já estão contidos no próprio material fônico da palavra, cuja essência remete sempre para um significado imanente e divino.

Tanto os fonemas quanto a etimologia das palavras revelam a Verdade de um ato de nomeação divina. Mas nem sempre a evolução diacrônica de uma palavra se presta a interpretações delirantes. Quando isto acontece, Vieira recorre a uma série de relações de similaridade com o objetivo de produzir um sentido inverso.

O Sermão de Santo António, "pregado em Roma, na Igreja dos Portugueses, e na ocasião em que o Marquês de Minas, Embaixador Extraordinário do Príncipe nosso Senhor fez a Embaixada de Obediência a Santidade de Clemente X", tem como proposição Santo António de Lisboa:

(...) E eu que me devo acomodar ao lugar e ao auditório, só falarei hoje de Santo António de Lisboa. 


\section{LITERATURA, PSICOPATOLOGIA}

Para Louvor, pois do Santo Português, e para honra e doutrina dos Portugueses que o celebramos, reduzindo estes dois intentos a um só assunto, e fundando tudo nas palavras do Evangelho: Vos estis lux mundi, será o argumento do meu discurso este: Que Santo António foi luz do mundo, porque foi verdadeiro Português; e que foi verdadeiro Português, porque foi luz do mundo. Declaro-me. Bem pudera Santo Antônio ser luz do mundo, sendo de outra nação; mas uma vez que nasceu Português, não fora verdadeiro Português se não for a luz do mundo, porque o ser luz do mundo nos outros homens, é só privilégio da Graça; nos Portugueses é também obrigação da natureza. Isto é o que hoje hão de ouvir os Portugueses de si e do seu Português. Ave Maria. (Vieira, 2001, Tomo 1, p, 280-281)

Em outro sermão, também intitulado Sermão de Santo António, pregado "em Roma, na Igreja dos Portugueses", Vieira se refere ao sermão anterior como panegírico. Aqui, ao reproduzir a versão mítica de que Lusitânia, antigo nome de Lisboa, foi fundada por Ulisses, retira dessa terra o sentido de luz:

(...) nenhuma terra há contudo entre todas as do mundo, que mais se oponha à luz, que a Lusitânia. Outra etimologia lhe dei eu no Sermão passado, mas como há vocábulos que admitem muitas derivações, e alguns que significam por antífrase o contrário do que soam; assim o entendo deste nome, posto que tão luzido. (Vieira, 2001, Tomo 2, p. 427-428)

Eis a justificativa retórica para a nova etimologia de Lusitânia:

(...) A terra mais ocidental de todas é a Lusitânia. E por que se chama Ocidente aquela parte do mundo? Porventura, porque vivem ali menos, ou morrem mais os homens? Não; senão porque ali vão morrer, ali acabam, ali se sepultam, e se escondem todas as luzes do firmamento. Sai no Oriente o Sol com o dia coroado de raios, como Rei e fonte de luz; sai a Lua e as Estrelas com a noite, como tochas acesas e cintilantes contra a escuridade das trevas, sobem por sua ordem ao Zênite, ${ }^{3}$ dão volta ao globo do mundo resplandecendo sempre a laminado terras e mares; mas em chegando aos Horizontes da Lusitânia, ali se afogam os raios, ali se sepultam os resplendores, ali desaparece e perece toda aquela pompa de luzes. (Vieira, 2001, Tomo 2, p. 428)

A raiz da palavra que designa os portugueses como lusitanos já contém em si o significado de trevas:

${ }^{3}$ Zênite: termo usado principalmente na astronomia para indicar um ponto de referência para a observação do céu.

Rev. Latinoam. Psicopat. Fund., São Paulo, 19(3), 544-554, set. 2016 
(...) O mundo, dizem os Gramáticos, que se chama mundo, Quia minem mundus; e a morte, Parca, Quia nemini parcit. E assim como o mundo se chama mundo, porque é imundo, e a morte se chama Parca, porque ninguém a perdoa, assim a nossa terra se pode chamar Lusitânia, porque a ninguém deixa luzir. (Vieira, 2001, Tomo 2, p. 428)

Em Sermão do Bom Ladrão, "pregado na igreja da Misericórdia de Lisboa, ano de 1655", Vieira, partindo da letra, quer como materialidade da palavra quer como escrita, joga com assonâncias fônicas ou com identificações anagramáticas: "Faltavam-lhe poucas letras a Adão para ladrão; e ao fruto para o furto não the faltava nenhuma" (Vieira, 2001, Tomo 1, p. 397).

A língua portuguesa se transforma, assim, em uma língua fundamental, em que todos os seus elementos já contêm em si mesmo o valor universal da Verdade. Desta forma, além dos fonemas e da etimologia, as letras também portam um sentido.

No Sermão de Nossa Senhora do Ó, a letra O representa a figura de um círculo: "A figura mais perfeita e mais capaz de quantas inventou a natureza, e conhece a Geometria, é o círculo" (Vieira, 2001, Tomo 1, p. 465). E, justamente por isso, essa letra representa a eternidade e o desejo porque "são duas cousas tão parecidas" (Vieira, 2001, Tomo I, p. 472). A eternidade, segundo a argumentação de Vieira, já tinha sido representada pelos caldeus e, posteriormente, pelos egípcios nos seus hieróglifos por um círculo, porque esta figura circular "não tem princípio, nem fim; e isto é ser eterno" (Vieira, 2001, Tomo I, p. 572). O desejo "ainda teve melhor pintor, que é a natureza. Todos os que desejam, se o afeto rompeu o silêncio e do coração passou à boca, o que pronunciam naturalmente é O" (Vieira, 2001, Tomo I, p. 472).

A partir daí o círculo adquire múltiplos significados: a própria forma do universo, o símbolo de Deus e o ventre da Virgem Maria, quando estava grávida do filho de Deus.

Vamos encontrar na obra de Vieira uma série de procedimentos paranoicos: ilusões megalomaníacas de grandeza (o Quinto Império), idealismos reformista e altruísta (o reino do Bem, a fraternidade entre as raças e os povos), erotismo (estado de exaltação) e pregação moral.

Nenhum exemplo ilustraria melhor esse delírio do que o seu projeto de escrever a história do futuro. Logo na abertura desse livro, Vieira anuncia que promete dizer as coisas que estão por vir e, portanto, apresentará uma nova e nunca vista história: “(... ) Portugal será o assunto, Portugal o centro, Portugal o teatro, Portugal o princípio e fim destas maravilhas; e os instrumentos prodigiosos delas os Portugueses" (Vieira, 1953, p. 18). 


\section{LITERATURA, PSICOPATOLOGIA}

O futuro de Portugal se refere a constituição do Quinto Império. Depois dos egípcios, dos assírios, dos persas e dos romanos, chegará a vez do Império que consumará o reinado de Cristo na terra sob a égide de Portugal. Para sustentar essa profecia, Vieira parte do seguinte raciocínio: o mundo dos antigos era dividido em três partes - África, Europa e Ásia; depois se descobriu a quarta parte, que era a América; falta ainda a quinta parte, chamada de Austral, que pertence ao futuro e será governada por Portugal. Aqui, mais do que em qualquer outro texto, explicita-se o caráter delirante do messianismo sebástico.

Para Vieira, Portugal no passado foi vencido, no presente é ressuscitado e no futuro será glorioso. Aqui, Vieira, incompreendido e perseguido, é escolhido por Deus para anunciar a bem aventurança aos homens. $\mathrm{O}$ engenho é submetido ao seu delírio de grandeza. Não basta mais pregar aos homens as lições da fé e catequizar os gentios. Ele se vê, depois de S. Matheus, S. Marcos, S. Lucas e S. João, como o quinto evangelista, cuja missão é terminar o trabalho iniciado pela vinda de Cristo à terra. Referindo-se ao profeta $\mathrm{S}$. João, diz que ele viu um anjo forte descer do céu com um livro na mão, e em seguida dá a sua interpretação: o anjo forte é Cristo, o livro é o evangelho explicado, o corpo místico é a Igreja e os dois pés são os pregadores apostólicos que levam pelo mundo Cristo e seu evangelho. O pé esquerdo está sobre a terra e o direito sobre o mar. $\mathrm{O}$ esquerdo simboliza os que ficaram na terra firme e pregaram nela. E o direito simboliza aqueles que foram a regiões distantes e remotas levar a fé de Cristo e a luz de seu Evangelho. Esta predicação o leva a concluir que o pé direito que Cristo pôs sobre o mar para essa gloriosa e evangélica empresa são, entre toda as nações do mundo, por excelência, os Portugueses.

Para terminar gostaria de ressaltar que o Padre António Vieira é, sem dúvida, o maior representante de uma tradição em que vigora um discurso que, durante muitos séculos, engendrou uma das versões míticas do que é ser português: um povo que vive das saudades de um tempo glorioso, que se sustenta nas esperanças de retorno a um passado resplandescente pela ressurreição de D. Sebastião, o rei morto na batalha de Alcácer Kibir.

\section{Referências}

Lacan, J. (1998). O estádio do espelho como formador da função do eu. In Escritos. Rio de Janeiro: Jorge Zahar. (Trabalho original publicado em 1949). 
Lacan, J. (1987). Da psicose paranoica em suas relações com a personalidade. Rio de Janeiro: Forense Universitária. (Trabalho original publicado em 1932).

Lacan, J. (1985). O seminário. Livro 3. As psicoses. Rio de Janeiro: Zahar. (Trabalho original publicado em 1955-56).

Saraiva, A. J. (1980). O discurso engenhoso. São Paulo: Perspectiva. Coleção Debates 124.

Vieira, P. A. (1953). Obras escolhidas. Pref. e notas de António Sérgio e Hernani Cidade. Lisboa: Livraria Sá da Cota. v. III História do Futuro I.

Vieira, P. A. (2001). Sermões. Org. Alcir Pécora. São Paulo: Hedra. 2v.

\section{Resumos}

(Padre António Vieira: Ingenious speech in the name of faith and the salvation of men)

In the seventeenth century, the sermon is the path to the evangelization of Catholicism. Baltazar Gracian, the great theorist of Baroque rhetoric, elaborates the standards for ingenious speech: skill and cleverness with words, a work of reconstruction of language. In his sermons, António Vieira puts ingenuity at the service of a discourse which is inscribed in one of the mythical versions of Portugal: a nation whose people wait to regain the glorious past of the age of Discovery, through the resurrection of Don Sebastian, the king who died in the battle of Alkácer Kibir.

Key words: Baroque, delirium, paranoia, Name of the Father

(Père António Vieira: Le discours ingénieux au nom de la rédemption de l'homme)

Au XVII siècle, le sermon est le moyen d'évangélisation de l'église catholique. Baltazar Gracián, le grand théoricien de la rhétorique baroque, élabore les règles du discours ingénieux: un savoir faire avec les mots, un travail de reconstruction de la langue. Dans ses sermons, le Père António Vieira utilise l'ingénieux au service d'un discours qui s'inscrit dans l'une des versions mythiques du Portugal: une nation dont le peuple attend avec la résurrection de Dom Sebastião, roi mort dans la bataille de Alkácer Kibir, la reconquête du passé glorieux de l'époque des grandes découvertes.

Mots clés: Baroque, délire, paranoïa, Non-du-Père hombre)

(Padre António Vieira: El discurso ingenioso en nombre de la salvación del

En el siglo XVII, el sermón es la vía de evangelización del catolicismo. Baltazar Gracián, el gran teórico de la retórica barroca, elabora las normas del discurso 
ingenioso: un saber hacer con la palabra, un trabajo de reconstrucción de la lengua. En sus sermones, padre Antonio Vieira coloca el ingenio a servicio de un discurso el cual se inscribe en una de las versiones míticas sobre Portugal: una nación cuyo pueblo espera, con la resurrección de Don Sebastián, el rey muerto en la batalla de Alkácer Kibir, reconquistar el pasado glorioso de la época de los descubrimientos.

Palabras clave: Barroco. Delirio. Paranoia. Nombre del Padre

(António Vieira: die geschickte Rede im Namen der Rettung des Menschen)

Im siebzehnten Jahrhundert ist die Predigt der Weg der Evangelisierung des Katholizismus. Baltazar Gracian, der große Theoretiker der Barock-Rhetorik, erarbeitet die Regeln für die geschickte Rede: Ein Umgang mit dem Wort, eine Arbeit des Wiederaufbaus der Sprache. In seinen Predigten stellt António Vieira seine Geschicktlichkeit im Dienste seinem paranoiden Delirium, das auf einer der mythischen Versionen von Portugal eingeschrieben ist: eine Nation, deren Menschen mit der Auferstehung von Don Sebastian - König, der in der Schlacht Alkácer Kibir zu Tode kam - die herrliche Vergangenheit im Zeitalter der Entdeckungen zurückerobern wollen.

Schlüsselwörter: Barock. Delirium. Paranoia. Name-des-Vaters.

(安东尼奥 . 维埃拉神父: 以信仰和拯救人类的名义作精巧式布道)

十七世纪, 神父的布道是天主教传教, 传达上帝福音的渠道。著名学者巴 尔塔萨尔 . 格拉希安 (BALTAZAR GRACIÁN), 巴洛克修辞专家, 列举出精巧式布道 的一些规则: 一是知道选择精巧的词语, 一是话语的重新构建。在安东尼奥. 维 埃拉神父的布道词里, 对葡萄牙, 他采用了精巧的神话般的描述: 把葡萄牙描 绘成一个等待塞巴斯提安国王复活的民族。塞巴斯提安国王是在北非的阿尔卡 瑟. 基比尔与摩尔人的战斗中阵亡的, 可是, 战争的目的却是为了恢复葡萄牙 在航海大发现时期所建立的荣耀。

关键词: 巴洛克, 谵妄, 偏执狂, 以天父之名

Citação/Citation: Ferreira, N. P. (2016, setembro). Padre António Vieira: o discurso engenhoso em nome da fé e da salvação do homem. Revista Latinoamericana de Psicopatologia Fundamental, 19(3), 544-554.

Editores do artigo/Editors: Vários

Rev. Latinoam. Psicopat. Fund., São Paulo, $19(3), 544-554$, set. 2016 


\section{LITERATURA, PSICOPATOLOGIA}

Recebido/Received: 20.1.2016/ 1.20.2016 Aceito/Accepted: 28.3.2016 / 3.28.2016

Copyright: (C) 2009 Associação Universitária de Pesquisa em Psicopatologia Fundamental/ University Association for Research in Fundamental Psychopathology. Este é um artigo de livre acesso, que permite uso irrestrito, distribuição e reprodução em qualquer meio, desde que o autor e a fonte sejam citados / This is an open-access article, which permits unrestricted use, distribution, and reproduction in any medium, provided the original authors and sources are credited.

Financiamento/Funding: Osautor declara não ter sido financiado ou apoiado / The author has no support or funding to report.

Conflito de interesses/Conflict of interest: $\mathrm{O}$ autor declara que não há conflito de interesses / The author has no conflict of interest to declare.

\section{Nadiá Paulo Ferreira}

Professora Titular de Literatura Portuguesa/Universidade do Estado do Rio de Janeiro/ UERJ (Rio de Janeiro, RJ, Br); Analista da Escola do Corpo Freudiano Escola de Psicanálise Seção Rio de Janeiro.

Rua Barão da Torre, 206/101 - Ipanema

22411-000 Rio de Janeiro, RJ, Br

nadia@corpofreudiano.com.br

This is an open-access article, which permits unrestricted use, distribution, and reproduction in any medium for non-commercial purposes provided the original authors and sources are credited. 